\title{
Investigation of Micro Hardness and Finite Element Analysis on Dental Implants
}

\author{
Pothamsetty Kasi V Rao ${ }^{1}$, G. Diwakar ${ }^{2}$, K. Sai Manideep ${ }^{3}$, Ankit Kumar Singh ${ }^{4}$ \\ ${ }^{1}$ Associate Professor, Department of Mechanical Engineering, Koneru Lakshmaiah Education Foundation, \\ Vaddeswaram, A.P., India, kasi_me@kluniversity.in \\ ${ }^{2}$ Professor, Department of Mechanical Engineering, Koneru Lakshmaiah Education Foundation, Vaddeswaram, \\ A.P., India, diwakar4236@kluniversity.in \\ ${ }^{3}$ Student, Department of Mechanical Engineering, Koneru Lakshmaiah Education Foundation, Vaddeswaram, \\ A.P., India, 160070173@ kluniversity.in \\ ${ }^{4}$ Student, Department of Mechanical Engineering, Koneru Lakshmaiah Education Foundation, Vaddeswaram, \\ A.P., India, 160070416@ kluniversity.in
}

\begin{abstract}
Dental implants are generally used for replacing the lost teeth or damaged teeth which occur due to oral disease or accidents. The selection of materials for such implants plays a vital role in Bio-medical field. The strength and bio compatibility are the challenging issues in identifying the appropriate material for Bio implants. The present study focuses on dental implants made of three different materials such as Stainless Steel, Nickel Chromium (Ni-Cr) and Titanium alloy. The micro hardness of dental implants made of stainless steel, titanium and nickel chromium are investigated using Vickers micro hardness test. The finite element analysis is performed on the models using ANSYS software to analyze the stress concentration on dental implant at different bite force. Finally the best material is suggested to use for Dental Implants.
\end{abstract}

Key words: Dental Implants, Bio-medical field, Micro hardness, Finite Element Analysis

\section{INTRODUCTION}

Materialsandtheiralloyshavebeenwidelyusedinallaspectsof science,engineeringand medicine. Metals in biomedical devices are utilized because of their inactivity and basic capacities. They are commonly favored over polymers or earthenware production and are particularly alluring in applications where the inserts are exposed to static, dynamic or

cyclicburdensthatrequireablendofsolidarityandflexibility.Inbi omedicine,thedecision of choosing a biomaterial is represented by numerous components that incorporate biocompatibility, erosion obstruction, controlled degradability, modulus of versatility, weakness quality and numerous other application explicitmeasures.

There are various biomaterials that can be utilized in the human body, for example, metals (for example tempered steel, cobalt amalgams, titanium combinations), earthenware production (aluminum oxide, zirconia, calcium phosphates), and engineered and common polymers. Among these, titanium and titanium compounds are the absolute most biomaterials, because of their protection from body liquid impacts, incredible elasticity, adaptability and high consumption opposition and this blend of solidarity and biocompatibility makes them reasonable for medicinal applications.
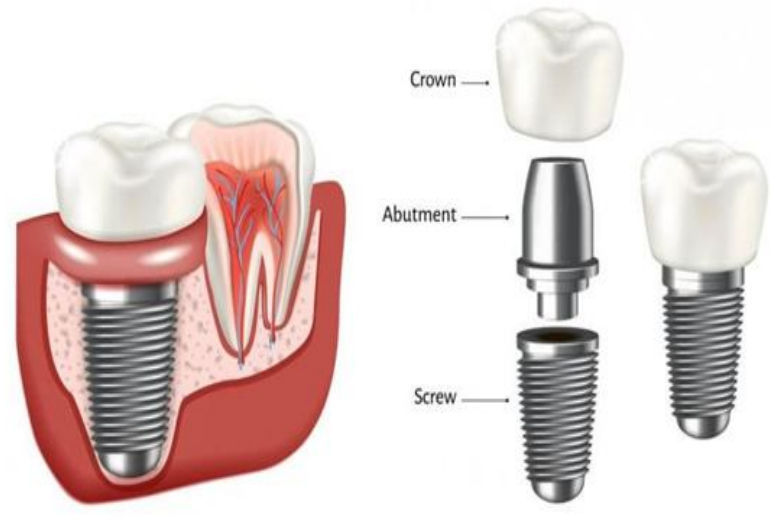

Figure 1: Dental Implantation

Finite element analysis (FEA) has been applied to investigate dental implant designs, the structure and material of the superstructure, and the stability of the surrounding bone [1-3]. The study on phase transformation of materials and their impact on the strength properties was examined for bone implants [4]. The bone samples with different stages of osteoporosis were modeled using finite element analysis and simulated with a Quadratic frequency modulated stimulus [5]. The usage of various manipulators for medical applications is taking a good pace now a days and the simulation of those devices are helpful in identifying the exact behavior [6]. Research on Co-Cr-W alloy when deposited with LENS, reveals that the material is suitable for the applications where high hardness and corrosion resistance are essential. The In-Vivo test results validated the biocompatibility of the material, which is proven by In-Vitro analysis for its suitability of medical applications. The LENS process is also proved to be suitable for customization of the size, shape and porosity of the components without changing the basic properties of the material [7-11]. The use of materials like Aluminium reinforced with CNTs metal matrix were playing prominent role in replacing the metals for many applications, 
especially in the field of medical engineering. The study of properties of such metal matrix materials using Finite element analysis is also attracting the researches in choosing best materials for bio-medical applications [12-15].

\section{SELECTiON OF MATERIALS}

2.1 Selection of Materials: Biomedical metallic materials are metals or compounds used to analyze, treat, fix, or supplantunhealthytissueinalifeformtoupgradeorreestablishitsc apacity, whichis utilized for the fix and substitution of hard tissues, for example, bones and teeth, for the fix of cardiovascular and delicate tissues, and for the production of counterfeit organs. The Biomaterial such as stainless steel, titanium and its alloys and nickel chromiumareusedinthisproject.Letdiscussaboutthepropertieso feachofmaterial.

\subsubsection{Titanium and its alloys}

Various new implant materials and models have been made since 1970, including the usage of polymers, porcelain, aluminum oxide (Alumina), bioactive glass (Bio-glass) and carbon materials. The most by and large used implant material, anyway nowadays, is titanium, which has gotten the greatest level for insert dentistry. Titanium and its mixes are used as prosthetic contraptions in dentistry as result of their extraordinary blend of manufactured, physical and natural properties. The American Society for Testing and Materials (ASTM International) perceives various evaluations of economically unadulterated titanium, and titanium amalgams (Ti-6Al-4V, Ti-5Al-1.5B, Ti-6Al-7Nb, and so on.). Clinically two sorts of titanium have gotten the most interest - modernly unadulterated titanium and Ti-6Al-4V.

\subsubsection{Stainless steel316L}

Stainless steel is an iron alloy with elements like chromium, nickel, silicon, manganese, nitrogen and carbon. Stainless steel particularly 316L sort is the most utilized metallic biomaterials for biomedical applications because of their great

biocompatibility,lowcost,magnificentconsumptionopposition ,accessibility,simple handling and high quality. Because of these good properties $316 \mathrm{~L}$ tempered steel has become the most appealing biomaterial for dental inserts and orthopedic inserts. In dentistry it is utilized in an assortment of utilizations, for example, transitorycrowns, sanitized instruments, curve wires, sections in orthodontics, and so forth. Stainless steel consists of 16-18 percentage of chromium due to which stainless steel is corrosion resistance.

\subsubsection{Nickel chromium metal}

The nickel-chromium framework uncovers that chromium is genuinely solvent in nickel. It has a most extreme dissolvable pace of $47 \%$ at eutectic temperature, which at that point diminishes to roughly $30 \%$ at room temperature. A few business combinations depend on this strong arrangement. These combinations have better opposition than high-temperature erosion and oxidation, and ideal wear resistance. Nickel-chromium alloys are one of the bio active material due to its goodmechanical properties such as corrosion resistivity. Corrosion resistivity properties of Nickel- chromium alloys make suitable to use for dental crown.

\section{FINITE ELEMENT ANALYSIS}

Stress analysis of dental implant of different bio metals are performed using ansys-16 software. Modeling of dental crown of diameter $6 \mathrm{~mm}$ and importing the dental crown model into the workbench static structure for the analysis of equivalent von-mises stress on thedentalcrownofdifferentmaterialsuchasstainlesssteel,titaniu malloysatvariousbite force. Applyingthedifferentbiteforcessuchas $200 \mathrm{~N}, 300 \mathrm{~N}, \quad 500 \mathrm{~N}$, 600 Nonthedental crown of material like titanium alloy, Stainless steel and compare the results obtain from theanalysis.

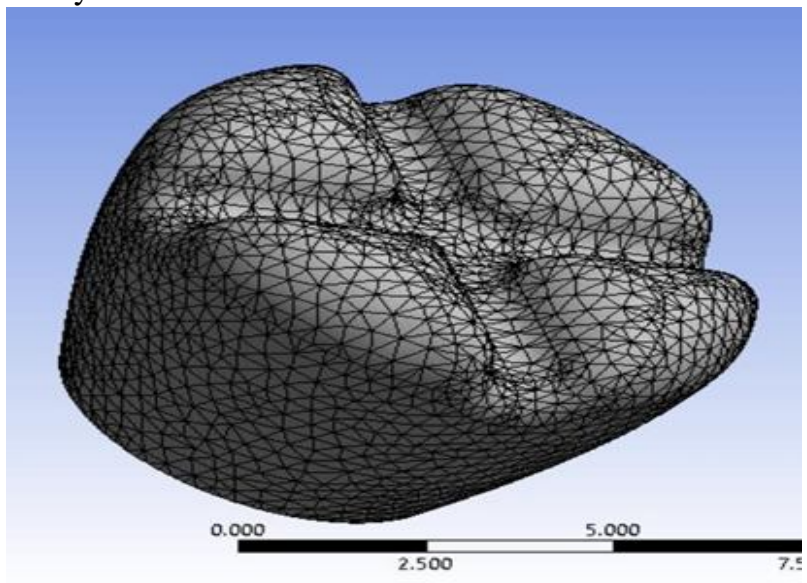

Figure 3.1 Modeling and Meshing of dental implant

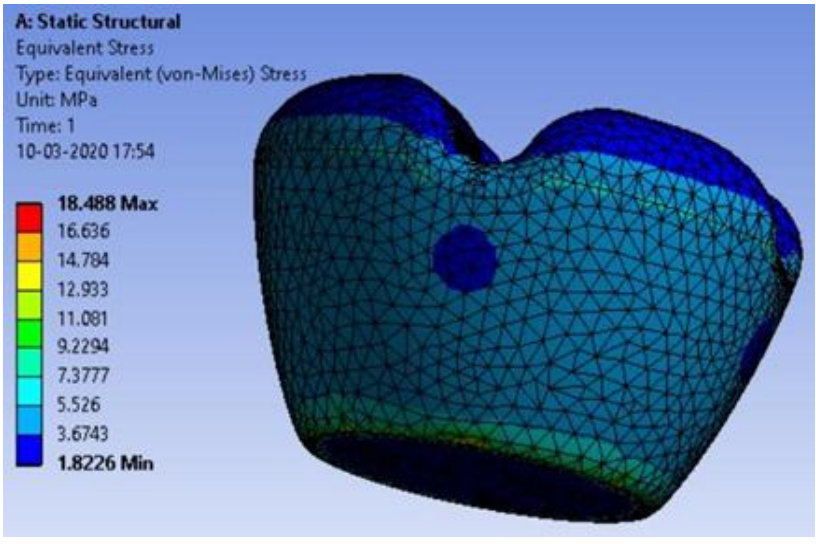

Figure 3.2 Von-Mises stress analysis at $200 \mathrm{~N}$ on Titanium alloy

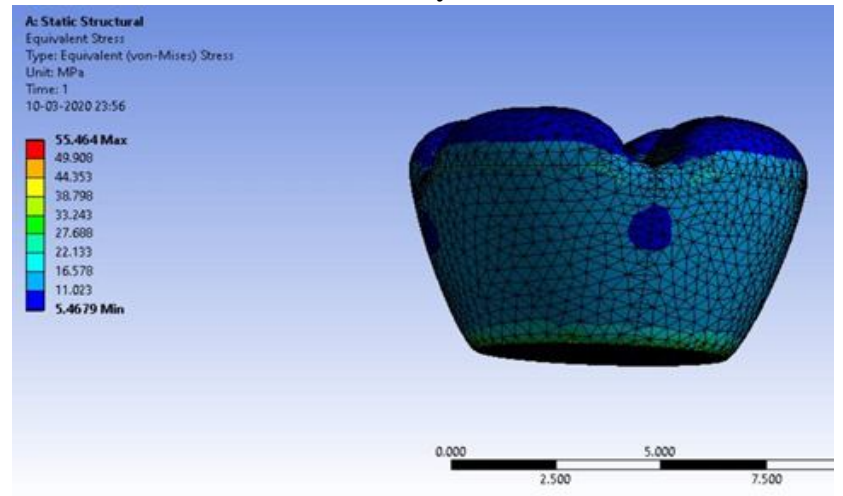

Figure 3.3 Von-Mises stress analysis at $600 \mathrm{~N}$ on Titanium alloy 


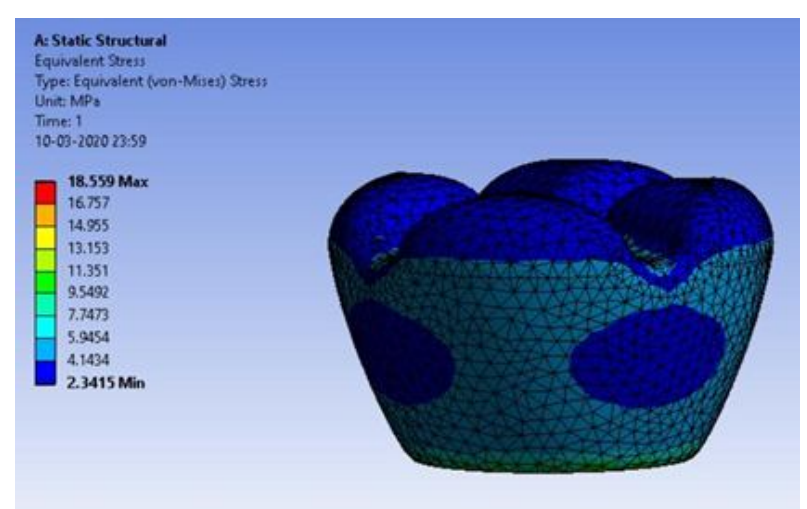

Figure 3.4 Von-Mises stress analysis at 200N on stainless steel

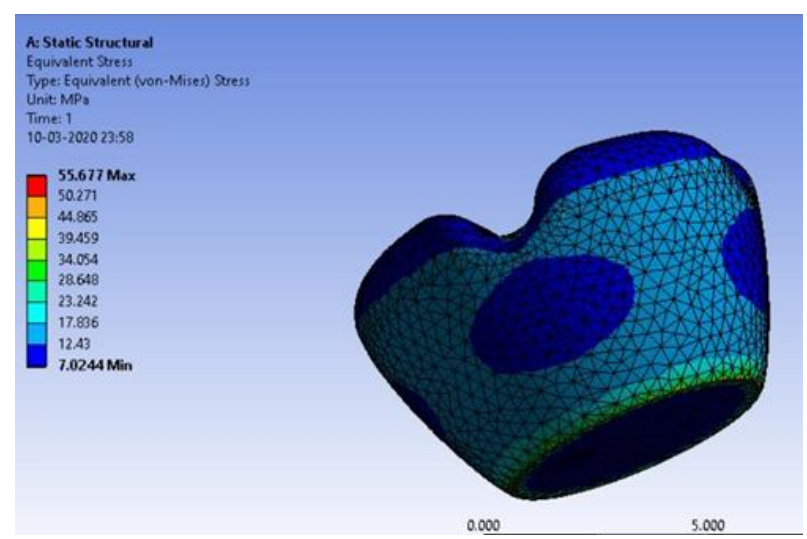

Figure 3.5 Von-Mises stress analysis at $600 \mathrm{~N}$ on stainless steel

Table 3.1: Von-Mises Stress values for different materials

\begin{tabular}{|c|c|c|}
\hline Material & Bite Force applied & Max. stress (MPa) \\
\hline \multirow{4}{*}{$\begin{array}{c}\text { Titanium } \\
\text { Metal }\end{array}$} & $200 \mathrm{~N}$ & 18.488 \\
\cline { 2 - 3 } & $300 \mathrm{~N}$ & 27.732 \\
\cline { 2 - 3 } & $500 \mathrm{~N}$ & 46.22 \\
\hline \multirow{4}{*}{\begin{tabular}{c} 
Stainless Steel \\
\cline { 2 - 3 }
\end{tabular}} & $600 \mathrm{~N}$ & 55.46 \\
\cline { 2 - 3 } & $200 \mathrm{~N}$ & 18.559 \\
\cline { 2 - 3 } & $300 \mathrm{~N}$ & 27.847 \\
\hline \multirow{3}{*}{$\begin{array}{c}\text { Nickel Chromium } \\
\text { Alloy }\end{array}$} & $500 \mathrm{~N}$ & 46.397 \\
\cline { 2 - 3 } & $600 \mathrm{~N}$ & 55.677 \\
\cline { 2 - 3 } & $200 \mathrm{~N}$ & 18.658 \\
\cline { 2 - 3 } & $300 \mathrm{~N}$ & 27.956 \\
\hline
\end{tabular}

After comparing the results obtained in ANSYS, dental crown made of titanium alloys are found to be best in terms of stress generated as compared to stainless steel funder variables bit load condition. So that we can say that the chance of failure of titanium alloys based dental implants is less as compared to the stainless steel in different bit loading condition.

\section{EXPERIMENTATION}

Micro hardness: Micro hardness tests are commonly used to study the physical properties of materials, and they are widely used to measure the hardness of teeth1-3. This method is easy, quick,

and requiresonlyatinyareaofspecimensurfacefortesting.Usingthist echnique,thespecimen surfaces were impressed with a diamond indenter (a Knoop or a Vickers) at a certain load for a certain period. After load removal, diagonals of the indentation were measured with an optical microscope.The hardness number was defined by the ratio between the indentation load and the area of the residual impression, which depended on the indenter shape. Then the hardness of materials was calculated using these equations:

$\mathrm{HK}=14230\left(\mathrm{~F} / \mathrm{d}^{2}\right)$ for Knoopmicrohardness or $\mathrm{HV}=1854$ $\left(\mathrm{F} / \mathrm{d}^{2}\right)$ for Vickers microhardness.

The constant value of each equation was calculated from the specific geometry of the indenter; $F$ was the indentation load $(\mathrm{g})$, and $\mathrm{d}$ was the diagonal of the indentation $(\mu \mathrm{m})$. The indentation load for the microhardness test can be performed using 1 to $1000 \mathrm{gm}$ and with various loading times. There is no agreement on the specifications of the conditions for the test method of a tooth. Vickermicrohardnes testing machine is used to measure the microhardness of materials. Vickermicrohardness is more accurate as compared to other micro hardness test.

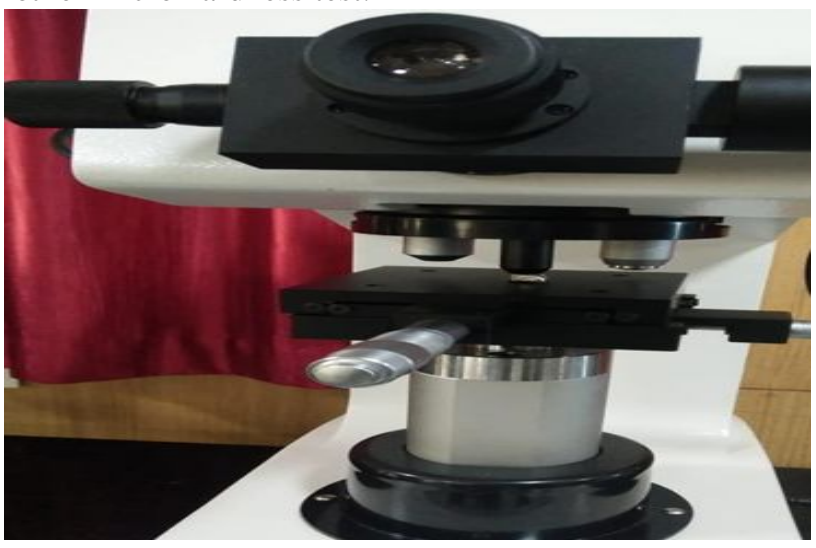

Figure 4.1 Vickers micro hardness tests machine A load of $100 \mathrm{~g}, 200 \mathrm{~g}$ and $300 \mathrm{~g}$ are applied on the different materials such as Nickel chromium, Titanium and stainless steel for 10 seconds in order to get indentation on the surface of metal. The indentation on the surface of metal is measured by the optical microscope.

Table 4.1: Indentation values for different loads

\begin{tabular}{|c|c|c|c|}
\hline Material & Load $(\mathbf{g})$ & D1 & D2 \\
\hline \multirow{3}{*}{$\begin{array}{c}\text { Nickel } \\
\text { Chromium alloy }\end{array}$} & 100 & 0.00 & 1.40 \\
\cline { 2 - 4 } & 200 & 7.59 & 15.31 \\
\cline { 2 - 4 } & 300 & 17.83 & 17.30 \\
\hline \multirow{3}{*}{ Titanium metal } & 100 & 11.11 & 9.47 \\
\cline { 2 - 4 } & 200 & 12.87 & 15.20 \\
\cline { 2 - 4 } & 300 & 15.99 & 14.95 \\
\hline \multirow{3}{*}{ Stainless steel } & 100 & 11.992 & 13.282 \\
\cline { 2 - 4 } & 200 & 5.59 & 9.85 \\
\cline { 2 - 4 } & 300 & 12.14 & 15.40 \\
\hline
\end{tabular}




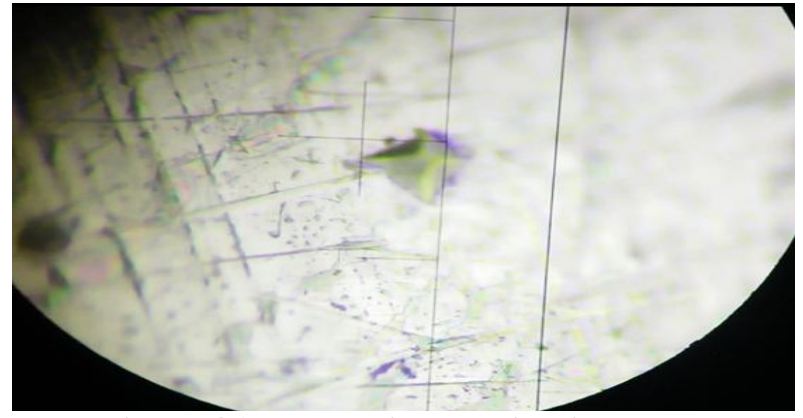

Figure 4.2 Indentation on Titanium alloy

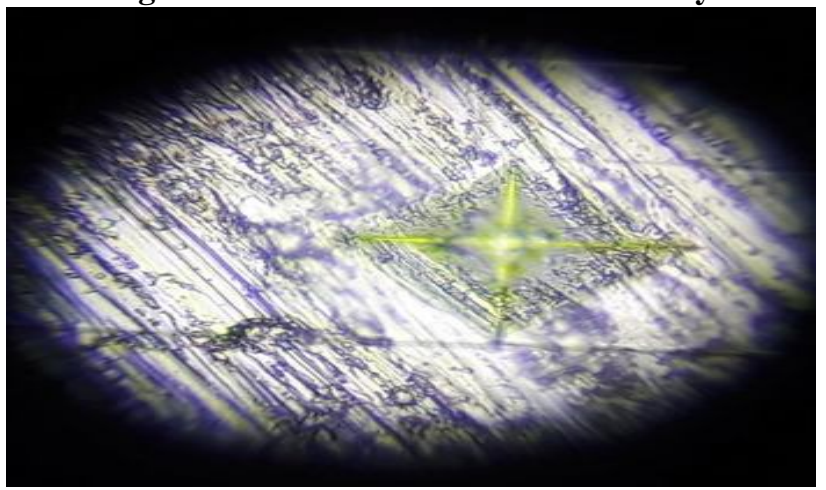

Figure 4.3: Micro indentation on stainless steel

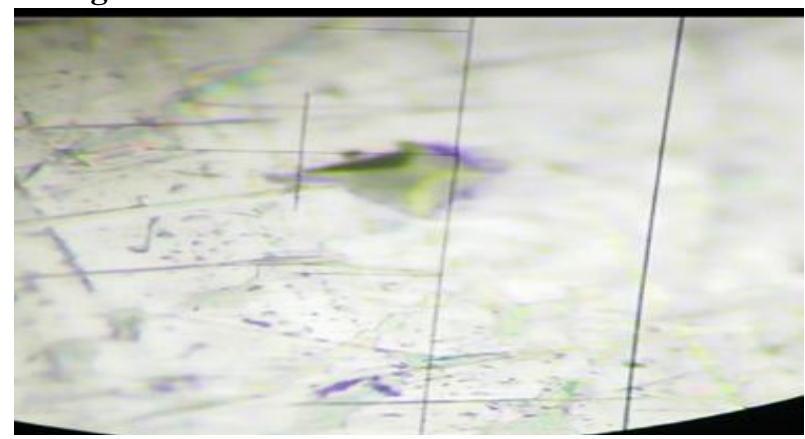

Figure 4.4: Micro indentation on Nickel Chromium

\section{CONCLUSION}

At load 100g, 200g and 300g, Vickers Hardness value is more for the titanium metal as compare to the stainless steel and Nickel chromium metals from above results shown in the table. Astitanium metal possesses more hardness values which means that titanium metal had good resistance of against penetration and scratching. If the hardness of metal is increases then resistance to wear and erosion by water, oil is increases. The dental implant materials should have good resistance to wear, penetration and scratching properties. All these properties are acquired by the titanium due to its high Vickers hardness. We can say that titanium have is more suitable for dental implant as compare to stainless steel and nickels alloys.

\section{REFERENCES}

[1] R. C. Van Staden, H. Guan \& Y. C. Loo (2006) Application of the finite element method in dental implant research, Computer Methods in Biomechanics and Biomedical Engineering, 9:4, 257-270, DOI: 10.1080/10255840600837074.

[2] Maminskas J, Puisys A, Kuoppala R, Raustia A, Juodzbalys $\mathrm{G},(2016)$, 'The prosthetic influence and biomechanics on peri-implant strain: a systematic literature review of finite element studies', Journal of Oral Maxillofacial Research, 7(3):e4.

[3] Gass SI. (1983), 'Decision-adding models: validation, assessment and related issues for policy analysis', Operations Research, 31, PP.603-631.

[4] Kholqillah Ardhian Ilman, Ngafwan. (2020), 'Preliminary study on the phase transformation of Ti-3Mo applying solid solution treatment for bone implant application', International Journal of Emerging Trends in Engineering Research, 8(6), PP.24019-2413.

[5] Badugu Suresh, K NikhelSathvik, Syed Imran, O V Gopi Reddy, V GopiTilak, A Vijayalakshmi, V S Ghali, (2020), 'Diagnosing Osteoporosis through Numerical Simulation of Bone Sample by Non-Stationary Thermal Wave Imaging', International Journal of Emerging Trends in Engineering Research, 8(3), PP. 776-779

[6] Kishore Kumar K., Srinath A., Harish M., Vijay P., Bhaskar K. (2017), 'Simulation of four arm parallel manipulator for medical applications',Journal of Advanced Research in Dynamical and Control Systems,9(Special Issue 18),PP.1802-1809.

[7] Suresh G., Narayana K.L., Mallik M.K. (2017),'Laser engineered net shaping process in development of bio-compatible implants: An overview',Journal of Advanced Research in Dynamical and Control Systems,9(Special Issue 14),PP.745-755.

[8] Suresh G., Narayana K.L., Mallik M.K.(2018), 'Bio-compatible processing of LENSTM DepositedCo-Cr-W alloy for medical applications', International Journal of Engineering and Technology(UAE) ,7(0), PP. 362-366.

[9] Suresh G., Narayana K.L., Mallik M.K., Srinivas V., Reddy G.J., Gurappa I.(2018), 'Electro chemical behaviour of lens ${ }^{\mathrm{TM}}$ deposited Co-Cr-W alloy for bio-medical applications', International Journal of Mechanical and Production Engineering Research and Development ,2018, PP. 41-52

[10] Suresh G., Narayana K.L., Kedar Mallik M., Srinivas V., Jagan Reddy G.(2018), 'Processing \& characterization of LENS $^{\mathrm{TM}}$ deposited $\mathrm{Co}-\mathrm{Cr}-\mathrm{W}$ alloy for bio-medical applications', International Journal of Pharmaceutical Research ,10(1), PP. 276-285

[11] Suresh G., Narayana K.L., Mallik M.K. (2019), 'Hardness, wear and corrosion properties of Co-Cr-W alloy deposited with laser engineered net shaping in medical applications', International Journal of Innovative Technology and Exploring Engineering, 8(8), PP.1951-1955.

[12] Rao P.K.V., Kumar B.R. (2019), 'Numerical estimation of hardness of carbon nanotubes reinforced al metal matrix', International Journal of Recent Technology and Engineering, 7(6), PP.1049-1052.

[13] Rao P.K.V., RaghuKumar B., Veera Sai Chandh Y., Teja A. (2019), 'Finite element analysis of CNT reinforced aluminium composite subjected to mechanical loading', Materials Today: Proceedings, 16, PP.308-313.

[14] Rao P.K.V., Gopisetti N.S.R., Chouhan S.G., Raghu Kumar B. (2019), 'Numerical model of toughness parameter for Al-MWCNT composites. An FEA case study', Materials Today: Proceedings, 16, PP.290-294.

[15] Rao P.K.V., Raghu Kumar B. (2019), 'Influence of size and weight fraction of carbon nanotube on coefficient of thermal expansion of Al-CNT metal matrix', Journal of Mechanical Engineering Research and Developments, 42(1), PP.85-89. 